\title{
Research on the efficiency of Mongolian large and medium commercial banks
}

\author{
Ma Zhanxin 1, a, Altantuya Batbaatar ${ }^{2, b}$ \\ ${ }^{1}$ School of economics and management, Inner Mongolia University, Hohhot 010021, China \\ ${ }^{2}$ School of economics and management, Inner Mongolia University, Hohhot 010021, China \\ a em_mazhanxin@imu.edu.cn, baltaaglory@yahoo.com
}

\begin{abstract}
Keywords: Commercial bank; Data envelopment analysis; Comprehensive efficiency; Technical efficiency.

Abstract. In recent years, Mongolian commercial banks have overcome many difficulties and developed rapidly, the commercial bank's overall operating efficiency is not high, and their efficiency is decreasing. Therefore, this paper first establishes the evaluation index system of Mongolian commercial banks. Then, the generalized data envelopment analysis method based on panel data is applied to analyze the comprehensive efficiency and technical efficiency of commercial banks in Mongolia. Finally, according to the results of efficiency analysis, the policy recommendations to enhance the efficiency of Mongolian banks are put forward. Also this has a certain significance to promote the Mongolian commercial banks to further improve their operational efficiency and overall strength.
\end{abstract}

\section{Introduction}

Commercial banks are an important part of the modern financial system of the country. In 80s, there was only one state bank in Mongolia. In April 1991, the Mongolia government promulgated the "Commercial Bank Law". This policy law plays an important role in the emergence and development of domestic commercial banks. By the end of 1992, there were 11 banks in Mongolia. At present, there are 14 commercial banks in Mongolia. In recent years, commercial banks in Mongolia have overcome many difficulties and developed rapidly, but the overall operating efficiency of commercial banks is not high, and their efficiency is decreasing. The academic circles have carried out a lot of research on the banking sector in Mongolia. L. Davaajargal (2000) studied the benefits of Mongolian commercial banks, and proposed that there is a correlation between the government bonds and the benefits of commercial banks ${ }^{[1]}$. G.Ariunkhishig (2004) researched the efficiency of commercial banks in Mongolia, and believes that the efficiency of large commercial banks have a downward trend, and the efficiency of medium-sized commercial banks have an upward trend ${ }^{[2]}$.

O.Oyuntsatsral (2013) has monitored the governance of commercial banks in Mongolia, and identified that the bank's governance is a great impact on the improvement of efficiency ${ }^{[3]}$. B.Munkhzaya (2013) studied the risk management of commercial banks in Mongolia, and proposed some measures to reduce the risk of commercial banks ${ }^{[4]}$. D.Bolitogtokh (2013) studied the process improvement of loans and deposits of commercial banks in Mongolia. Using the parametric and nonparametricmethod has taken to improve the commercial bank's efficiency ${ }^{[5]}$. O.Odkhuu and D.Nyamdavaa (2012) using the DEA model analyzed 2008 to 2011 input and out data of four lager Mongolian commercial bank ${ }^{[6]}$.Although a lot of scholars have carried out a lot of thesis on commercial banks in Mongolia, most of them focus on the crisis and prediction of commercial banks, and the thesis on the efficiency analysis of commercial banks is less. Therefore, this paper first establishes the evaluation index system of Mongolia commercial banks. Then, the generalized data envelopment analysis method based on panel data is applied to analyze the comprehensive efficiency and technical efficiency of commercial banks in Mongolia. Finally, according to the results of efficiency analysis, the policy suggestion to enhance the efficiency of Mongolian banks are put forward. This has a certain significance to promote the commercial banks in Mongolia to further improve their operational efficiency and overall strength. 


\section{Economic performance evaluation method based on panel data}

This paper selects three input indicators and two output indicators. Three input indicators are the net value of the fixed assets (FA), the number of employees (NE), and the deposit (DE) .As two output indicators are the net interest income (NI) and the loan (LN).

It is assumed that there are $b$ banks, in which the input index values of the $j$ th bank in base year (control group) are $\left(F A_{j}^{(0)}, N E_{j}^{(0)}, D E_{j}^{(0)}\right)$, and the output index values are $\left(N I_{j}^{(0)}, L N_{j}^{(0)}\right)$; and the input index value of the year $k t h$ is $\left(F A_{j}^{(k)}, N E_{j}^{(k)}, D E_{j}^{(k)}\right)$, and the output index value is $\left(N I_{j}^{(k)}, L N_{j}^{(k)}\right)$, $j=1,2, \ldots, b, k=1,2, \ldots, n$.

In order to investigate the efficiency of banks relative to base year, we give a set of production in base year as follows:

$$
\begin{gathered}
T_{\text {bank }}=\left\{(F A, N E, D E, N I, L N) \mid(F A, N E, D E) \geq \sum_{j=1}^{b}\left(F A_{j}^{(0)}, N E_{j}^{(0)}, D E_{j}^{(0)}\right) \mu_{j},\right. \\
\left.(N I, L N) \leq \sum_{j=1}^{b}\left(N I_{j}^{(0)}, L N_{j}^{(0)}\right) \mu_{j}, \delta \sum_{j=1}^{b} \mu_{j}=\delta,\left(\mu_{1}, \mu_{2}, \ldots, \mu_{b}\right) \geq 0\right\}
\end{gathered}
$$

Definition 1 For $\left(F A_{j}^{(k)}, N E_{j}^{(k)}, D E_{j}^{(k)}, N I_{j}^{(k)}, L N_{j}^{(k)}\right)$, if it does not exist $(F A, N E, D E, N I, L N) \in T_{\text {bank }}$, satisfies $\left(F A_{j}^{(k)}, N E_{j}^{(k)}, D E_{j}^{(k)}\right) \geq(F A, N E, D E),\left(N I_{j}^{(k)}, L N_{j}^{(k)}\right) \leq(N I, L N),\left(F A_{j}^{(k)}, N E_{j}^{(k)}, D E_{j}^{(k)}, N I_{j}^{(k)}, L N_{j}^{(k)}\right) \neq(F A$, $N E, D E, N I, L N)$, we call the evaluated unit $j$ is D-panel effective

By definition 1, if the evaluated unit is D-panel effective, which means that the production status of the evaluated unit is not inferior to the optimal production state in the period of basis time.

$$
(D-\text { Panel })\left\{\begin{array}{c}
\min \left[\theta_{j}^{(k)}-\varepsilon\left(s_{1 j}^{(k)}+s_{2 j}^{(k)}+s_{3 j}^{(k)}+s_{4 j}^{(k)}+s_{5 j}^{(k)}\right)\right]=V_{D} \\
\text { s.t. } \sum_{i=1}^{b} F A_{i}^{(0)} \mu_{i j}^{(k)}+s_{1 j}^{(k)}=\theta_{j}^{(k)} F A_{j}^{(k)} \\
\sum_{i=1}^{b} N E_{i}^{(0)} \mu_{i j}^{(k)}+s_{2 j}^{(k)}=\theta_{j}^{(k)} N E_{j}^{(k)} \\
\sum_{i=1}^{b} D E_{i}^{(0)} \mu_{i j}^{(k)}-s_{3 j}^{(k)}=\theta_{j}^{(k)} D E_{j}^{(k)} \\
\sum_{i=1}^{b} N I_{i}^{(0)} \mu_{i j}^{(k)}-s_{4 j}^{(k)}=N I_{j}^{(k)} \\
\sum_{i=1}^{b} L N_{i}^{(0)} \mu_{i j}^{(k)}-s_{5 j}^{(k)}=L N_{j}^{(k)} \\
\delta \sum_{i=1}^{b} \mu_{i j}^{(k)}=\delta \\
s_{1 j}^{(k)}, s_{2 j}^{(k)}, s_{3 j}^{(k)}, s_{4 j}^{(k)}, s_{5 j}^{(k)} \geq 0, \mu_{i j}^{(k)} \geq 0, i=1,2, \cdots, b
\end{array}\right.
$$

The $\varepsilon$ is non Archimedes infinitesimal, $\delta=0$ or 1 , when $\delta=0$ is calculated is the comprehensive efficiency of the decision unit. When $\delta=1$, the calculation is the technical efficiency of the decision unit. The model (D-Panel) has the following properties:

Theorem 1 If the model (D-Panel)has an optimal solution $\theta_{j}^{(k)}, s_{h j}^{(k)}, \mu_{i j}^{(k)}$ satisfies $\theta_{j}^{(k)}>1$ or $\theta_{j}^{(k)}=1$ then $\left(s_{1 j}^{(k)}, s_{2 j}^{(k)}, s_{3 j}^{(k)}, s_{4 j}^{(k)}, s_{5 j}^{(k)}\right)=0$, then $j$ th bank efficency of $k$ th year is effective.

\section{An empirical analysis of Mongolian commercial banks' efficiency}

In order to further analyze the current situation of commercial banks in Mongolia, the following 8 years data of the 2008-2015 period in Mongolian 10 commercial banks are collected, and the comprehensive efficiency and technical efficiency of each bank are calculated by using the model (D-Panel). The results are as follows.

3.1 The comprehensive efficiency analysis of Mongolian commercial banks

According to the 2008-2015 data of the commercial bank (State bank's 2008 data loss), the results of the comprehensive efficiency analysis for each bank is obtained by $\delta=0$ and the application model (D-Panel). 
(1) Average comprehensive efficiency analysis of each Mongolian banks

As can be seen from Figure 1, the average overall efficiency rankings of Mongolian banks from 2008 to 2015 are:

State bank $<$ Capitron bank $<$ NI bank $<$ Capital bank $<$ Khaan bank $<$ Chinggis khan bank $<$ UB bank $<$ Xac bank $<$ TDBbank $<$ Golomt bank

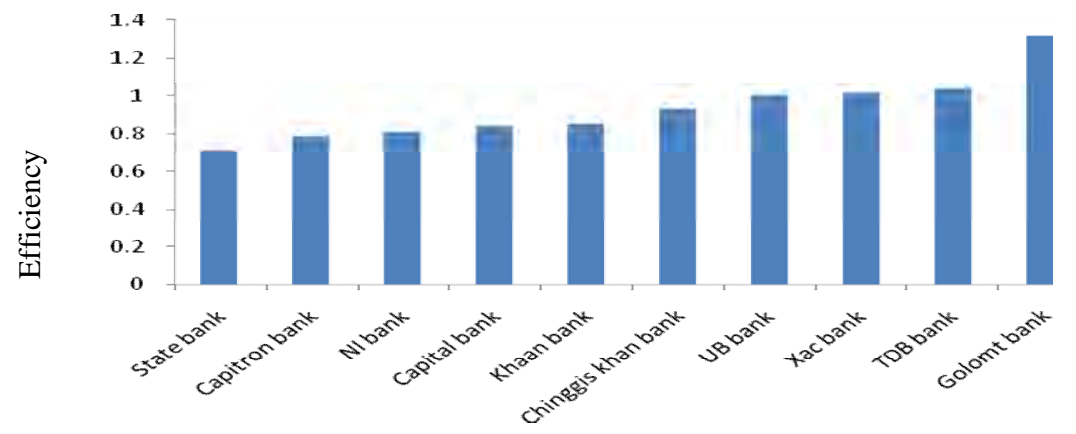

Figure 1.The average comprehensive efficiency of commercial banks in Mongolia

Then the average efficiency of Golomt bank ismost high, which is 1.3170, followed by TDB bank, and Xac bank. The average efficiency of State banks is most lower which is 0.7129 . In 2015, the average overall efficiency is 0.8642 . This is mainly due to the appropriate measures taken by TDB bank and more cooperation with foreign banks. TDB bankcooperated with Netherlands Development bank(FMO) and ING Bank to obtain the loan facility agreement in 2013. Also TDB went to the Singapore's capital market successfully for a fifth time with a CNY 700 million offshore renminbi bond in 2014. And State bank was taken over by the state as early as 2008 because of the manager's erroneous decision and lost the ability to pay.

(2) The comprehensive efficiency analysis of Mongolian commercial banks

Figure 2 is showed the changing trend of the efficiency of Mongolia's commercial banks in 2008-2015.

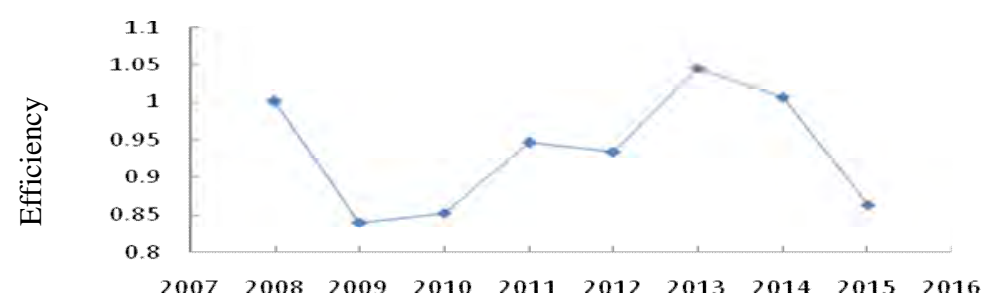

Fig 2 Comprehensive efficiency trend of Mongolian commercial banks in 2008-2015

It can be seen from Figure 2, the average overall efficiency of Mongolian banks during the period from 2008 to 2015 experienced a drop, then up and drop. Following the economic crisis of 2008, the bank's efficiency decreased in 2008 and 2009. The average comprehensive efficiency is showed rising trend in the period 2010 to 2013. But after 2013, the comprehensive efficiency is decreased rapidly. However Mongolian economic is upset and all of Mongolia's banks lend out mining sector during this period. Then the reduction of the price of Mongolia's export mineral resources in the international market led to the serious loss of some enterprises and slow down these company's ability to repay the loans. It has a great impact on the efficiency of commercial banks.

3.2 Technical efficiency analysis of Mongolian commercial bank

If $\delta=1$, the technical efficiency of the banks can be obtained by applying the model ( $D$-Panel) .

(1) The average technical efficiency analysis of each bank

As can be seen from Figure 3, the average technical efficiency rankings of Mongolian banks from 2008 to 2015 are:

State bank $<$ Capital bank $<$ Khaan bank $<$ Capitron bank $<$ TDB bank $<$ Xac bank $<$

Chinggis khan bank $<$ NI bank $<$ UB bank $<$ Golomt bank 


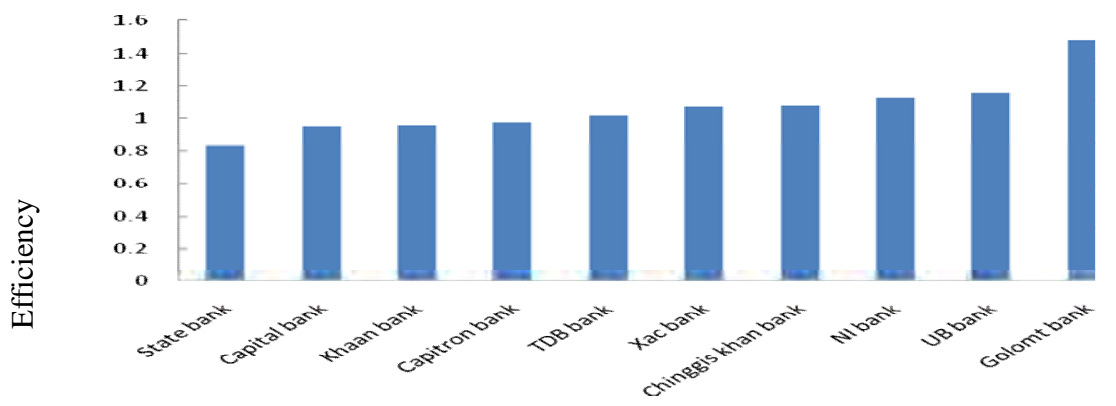

Figure 3.The average technical efficiency of commercial banks in Mongolia

Among them, Golomt bank has the highest average technical efficiency of 1.4821, while State bank has the lowest average technical efficiency of 0.8356. In 2015, the average overall efficiency was 0.8642 .

(2) The technical efficiency analysis of Mongolia's commercial banks

Figure 4 is showed the changing trend of the technical efficiency of Mongolia's commercial banks in 2008-2015.

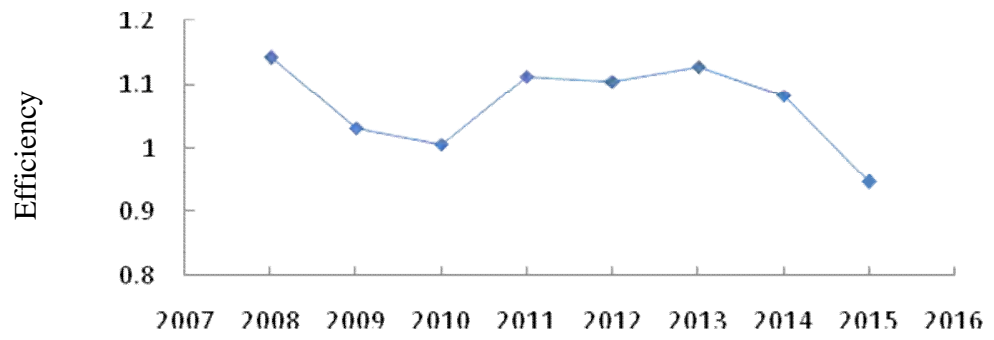

Fig 4Technical efficiency trend of Mongolian commercial banks in 2008-2015

As can be seen from Figure 4, the average technical efficiency of Mongolian banks in the 2008-2013 has maintained a stable trend except for 2009 and 2010. But from 2013, technical efficiency also showed that downward trend.

\section{Acknowledgements}

This work was financially supported by National Natural Science Foundation of China (71261017, 70961005), Natural Science Foundation of Inner Mongolia (2016MS0705) and Inner Mongolia Prairie Excellence Specialist Project (12000-12102012).

\section{References}

[1] L. Davaajargal. The improve method of commercial bank's laons and deposits [D] .Ulaanbaatar. 2000

[2] G. Ariunkhishig. The indicator dynamic of bank profitablity in commercial bank and non banks sector[D],Ulaanbaatar, 2004.

[3] O. Oyuntsatsral. Way to develop the corporate governance in banking sector governance [D]. Ulaanbaatar, 2013

[4] B. Munkhzaya. The methodology to improve risk management of commercial banks in the financial crisis [D]. Ulaanbaatar, 2013

[5] D. Bolitogtokh. The methodology to upgrade the deposits and lians measures in Mongolian commercial banks [D]. Ulaanbaatar, 2013

[6] O. Odkhüü, D. Nyamdavaa. Calculation the commercial bank efficiency [D] .Ulaanbaatar, 2012 